\title{
Carbon Emission from Transportation and Carbon Sink Forest in Road
}

\author{
Lijuan Wan ${ }^{1,2}$, Yi Zhang ${ }^{1,2^{*}}$ and Dongxiang Cheng ${ }^{1,2}$ \\ ${ }^{1}$ Nanjing Communications Institute of Technology, Nanjing 211188, China; \\ 2 Jiangsu Engineering Technology Research Center for Energy Conservation and Emission \\ Reduction of Transportation, Nanjing 211188, China.
}

Corresponding Author: Yi Zhang

Keywords: Carbon emission, carbon sink forest, transportation.

\begin{abstract}
In this paper, taken the city Nanjing in China as the sample, the carbon emission from transportation is analyzed. To reduce the greenhouse gases produced by transportation, the carbon sink forest in road is investigated, based on the idea of the forest carbon sinks. To increase the greening quality along the roads and update the greening idea, enhancing carbon fixation and ecological efficiency is important to realize the low carbon, energy saving and emission reducing in transportation. For the carbon sink forest in road, the carbon sequestration capacity of different kinds of trees should be investigated and the measurement of carbon sink and carbon sink monitoring are the key technology.
\end{abstract}

\section{Introduction}

With the increasing development of global economy, the environmental and ecological problems attract the attention of more and more people. With the recent economic boom in China, there has been a steep rise in energy consuming, solved by the increasing use of fossil fuels. $\mathrm{CO}_{2}$ emissions from fossil-fuel have thus increased from 0.4 $\mathrm{PgC} \mathrm{yr}^{-1}$ in 1980 to $1.5 \mathrm{PgC} \mathrm{yr}^{-1}$ in 2006, making China the largest emitter in the world [1]. Due to the source consuming, the emission of greenhouse gases induced the global temperature increasing and extreme abnormal climate phenomena appearing more and more frequently. Reducing the global temperature and the content of carbon dioxide in the atmosphere has received the global attention.

Due to close relation between global change of climate and carbon cycle in global system, the carbon cycle in global system and the proceeding mechanism become the reason analyzing and anticipating the changing trend and reducing of climate changing, which received the wide attention of the science and technology community and the international community [2,3]. The carbon cycle of the earth system refers to the biogeochemical processes of the exchange and flow of carbon elements in the atmosphere, oceans, land and the carbon pool of the lithosphere. It is the largest biogeochemical cycle on earth. It is through the photosynthesis of plants to fix the $\mathrm{CO}_{2}$ of the atmosphere to the organic matter and convert the solar energy into chemical energy. Thus it becomes the most basic material and energy source in the human production and life. When the biosphere and the atmospheric system are in a dynamic equilibrium, carbon cycle is also in a dynamic equilibrium. $\mathrm{CO}_{2}$, which is absorbed from the atmosphere, is almost equally released into the atmosphere. But in the past century, a large number of human use of fossil fuels, coupled with changes in land use, which makes the atmospheric $\mathrm{CO}_{2}$ concentration significantly increased, breaking the original carbon balance between the biosphere and the atmosphere, and triggered a series of major environmental problems such as global warming and sea level rise [4].

From a global point of view, the transportation industry in the world's energy consumption and greenhouse gas emissions is in the proportion of more than $20 \%$, and still shows a rapid upward trend, energy saving and emission reduction is a major responsibility. Countries in the world will develop green, low-carbon transport as a strategic focus. China's transportation industry as one of the key areas of energy consumption and greenhouse gas emissions, in 2008, transportation oil consumption accounts for about $36 \%$ of the total oil consumption in the country, of which the proportion of road 
transport and transportation in the transportation industry is about $44 \%$. China's greenhouse gas emission reduction target situation is grim.

\section{Evolution Process of Carbon Emission from Transportation in Nanjing City}

\subsection{Population profile}

To the end of 2012, according to the statistical yearbook of Nanjing City, Nanjing resident population reached eight million one hundred and sixty-one thousand. According to data from 2005 to 2012, in Fig. 1, it can be seen that from 2005 to 2012 period, the population growth is on the rise, reduced from 4.24\% in 2006 to $1.64 \%$ in 2009. In 2010, Nanjing city resident population increase reached $3.81 \%$, and from the beginning of 2011, the population growth rate reduced gradually. The trend is shown in Fig.1.

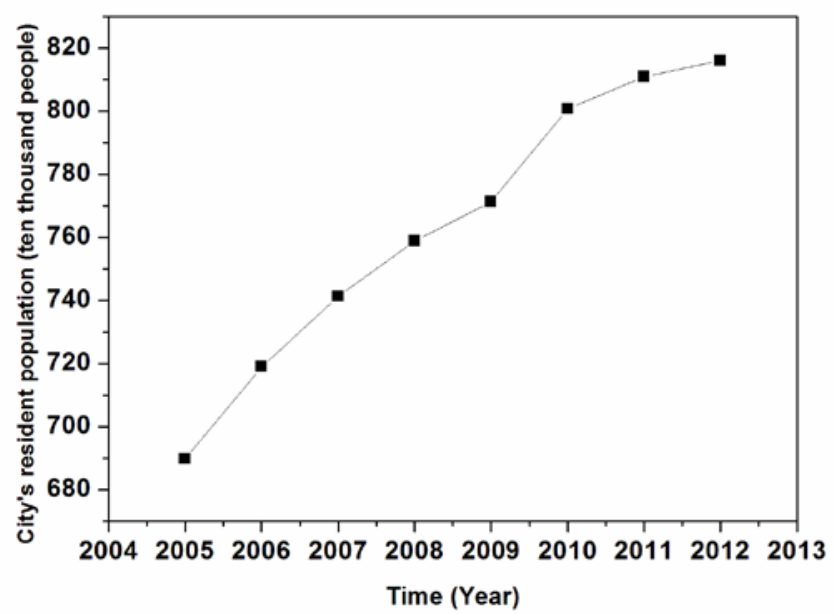

Fig. 1 Resident population of Nanjing City.

\subsection{Public transport survey}

Nanjing public transport is composed by bus, taxi and subway. While the number of taxi in Nanjing, from 2006 to the present, the number remained unchanged, at around 10600. And for the number of public buses as shown in Fig. 2, from 15455 in 2006 increased to 20029 in 2012, the overall increase in the more than 4500 vehicles, but the average growth rate is not to 5\% (4.45\%), especially from $2.25 \%$ growth in 2011 to $1.56 \%$ in 2012, and an average of bus number owned per million people was 24.54 vehicles, which cannot fully meet the travel needs of residents.

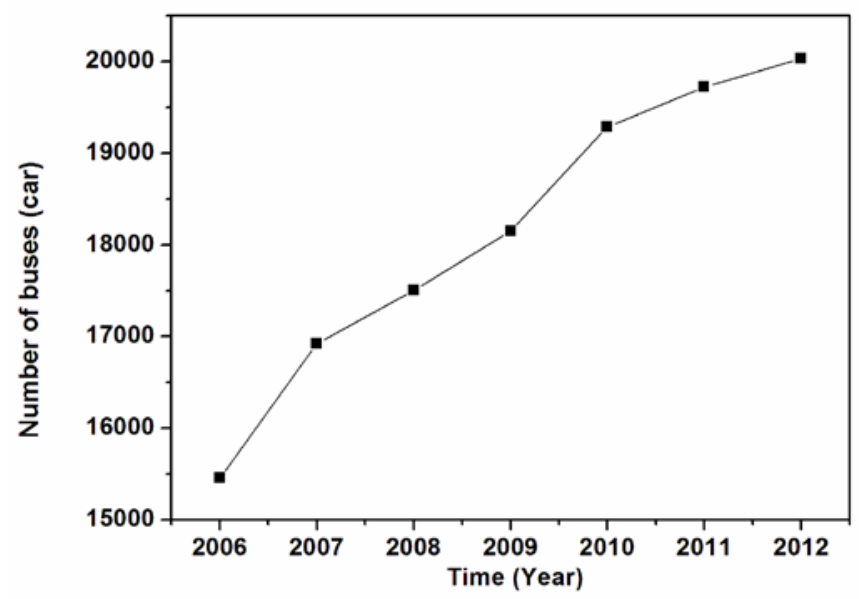

Fig. 2 Number of buses

\subsection{Overview of private cars}

Different from the population and the number of public buses growth chart, the growth rate of the number of private cars is very large, and the average value of the nearly seven years reaches $25.28 \%$, and in 2007 the growth rate reached a record high of 32.09\%. As shown in Fig. 3, since the beginning of 2006, the growth rate private car ownership per year is more than $19 \%$, the growth rate 
respectively reaches $32.09 \%, 22.95 \%, 28.35 \%, 26.78 \%, 22.09 \%$ and $19.40 \%$, and in 2012 it reached 797429 vehicles. A large number of private cars can not only cause traffic congestion, but also consume a lot of energy and emit a large amount of exhaust gas, causing the pollution of urban environment.

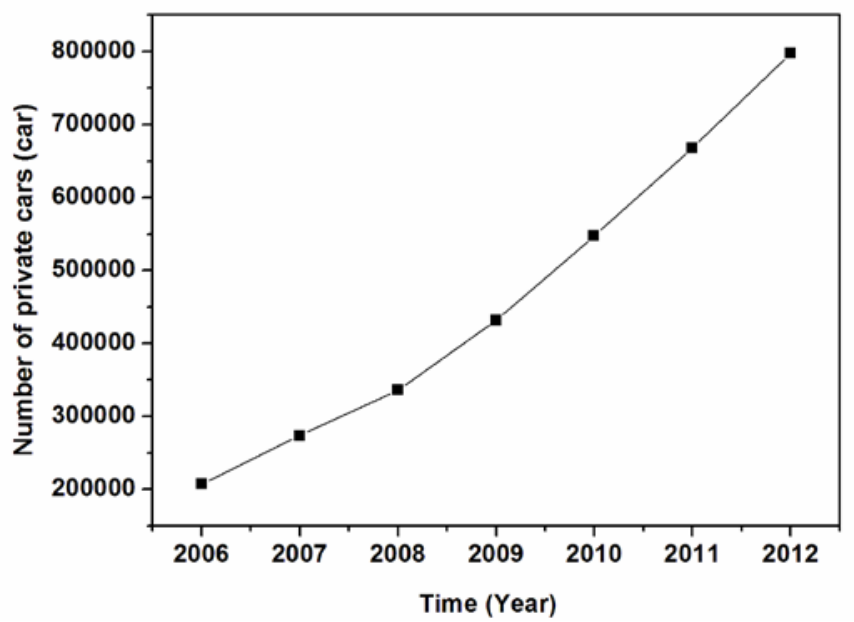

Fig. 3 Number of private cars

\subsection{Current situation of emission of traffic}

As a national pilot city of low carbon, Nanjing city strive to find a balance point in the development of urban economy and energy saving and emission reduction work, to realize low carbon development. At the same time as private car ownership has increased rapidly and the problem of urban traffic congestion is becoming more and more serious, reducing transport energy consumption and carbon emissions has become an important starting point of development of low carbon economy. Due to lack of transport energy consumption statistics in the "statistical yearbook of Nanjing" and other information, the energy consumption of the city bus, taxi were calculated to measure transportation energy consumption since 2010, as shown in Table 1:

Table 1Transportation carbon emission Scheme

\begin{tabular}{lrrr}
\hline \multicolumn{1}{c}{ NumberlYear } & \multicolumn{1}{c}{2010} & \multicolumn{1}{c}{2011} & \multicolumn{1}{c}{2012} \\
\hline Public steam tram (car) & 7780 & 7953 & 8186 \\
$\mathrm{CO}_{2}$ emissions from gasoline (ton) & 26213.71 & 49766.17 & 58811.31 \\
$\mathrm{CO}_{2}$ emissions from diesel oil (ton) & 243004.84 & 259675.84 & 285192.14 \\
$\mathrm{CO}_{2}$ emissions from natural gas (ton) & 82722.8 & 62374.47 & 58514.47 \\
Taxi (car) & 10593 & 10644 & 10643 \\
$\mathrm{CO}_{2}$ emissions from gasoline (ton) & 79042.88 & 239152.03 & 186344.65 \\
$\mathrm{CO}_{2}$ emissions from diesel oil (ton) & 2586.87 & 17867.25 & 33.19 \\
$\mathrm{CO}_{2}$ emissions from natural gas (ton) & 45621 & 47294.59 & 114527.99 \\
\hline
\end{tabular}

Through the analysis of the current situation of urban traffic in Nanjing City, it is mainly shown from the population of Nanjing City, the status of public transport, especially the development of public transport, and the ownership of private cars. It was found that the development of public traffic is relatively backward which cannot fully meet the needs of residents travel in Nanjing City, and the number of private cars are at high growth year after year, which not only caused urban congestion, but also consumes a large amount of energy and greenhouse gas emissions. Combined with the specific objectives of Nanjing city transportation plan, to accelerate the development of energy-saving and low carbon new modes of transportation, to accelerate new technology, to promote the optimization of transportation structure, and green traffic system is built. 


\section{Carbon Sink Forest in Road}

Forests are a source of timber for fuel and also considered to be carbon sinks which absorb the excess carbon dioxide from the air and provide oxygen and they play an important role in the global carbon cycle since trees and other forest plants convert carbon dioxide to carbon through photosynthesis [5]. For reducing the greenhouse gases produced by transportation, the carbon sink forest in road is investigated. Study on carbon sink forest in road is mainly focused on as follows: (1) Project baseline survey and data analysis: Reference to "guidelines for the measurement and monitoring of carbon sequestration in afforestation projects", and land quality and carbon pool are selected. Project area stratification and sample quantity are determined. Through literature research, field investigation and expert opinion, carbon storage size is predicted. To choose carbon pool with the comprehensive analysis of the changes in time, the above ground part and underground part and soil carbon pool intends to be chosen for the measurement of the carbon pool; (2) Research on measurement and monitoring method of carbon sink forest: Research on plant biomass and skidding quantity and solid carbon, survey of carbon storage in existing road on both sides of the forest and quantitative analysis of carbon sink function of plant within the road should be proceeded. The methodology of carbon sink monitoring and measurement in the road green region should be investigated; (3) Study on optimal allocation model of forest carbon sink: According to the measurement and monitoring of forest carbon sink, with the purpose of giving priority to the local nursery stock, in accordance with the fixed carbon content of the principle of maximum, tree species are selected and the corresponding optimal allocation model is established, and the 5 to 10 kinds of trees are determined.

\section{Summary}

The carbon emission from transportation in Nanjing is analyzed. To accelerate the development of energy-saving and low carbon new modes of transportation is for the specific objectives of Nanjing city transportation plan, and green traffic system is to be built. The carbon sink forest in road is investigated for reducing the greenhouse gases produced by transportation to realize the development of low carbon road. For the carbon sink forest in road, the key technology is the measurement of carbon sink and carbon sink monitoring.

\section{Acknowledgement}

This work was supported by a grant from Transportation Scientific Research Project of Jiangsu Province, Jiangsu Provincial Communications Department (2016Y21) .

\section{References}

[1]. Shilong Piao, Jingyun Fang, Philippe Ciais, et al. The carbon balance of terrestrial ecosystems in China, Nature, Vol. 458 (2009) No. 23, p. 1009-1013.

[2]. Guirui Yu, Xiaomin Sun. Principle and method of terrestrial ecosystem flux observation. Beingjing: Higher Education Press, 2006.

[3]. Guirui Yu, Qiufeng Wang, Xianjin Zhu. Carbon budget assessment method and its uncertainty in regional scale terrestrial ecosystem. Progress in Geographical Science, Vol. 30 (2011) ) No. 1, p. 103-113.

[4]. Intergovernmental Panel on Climate Change (IPCC). Climate Change 2007: The Physical Science Basis. Contribution of Working Group I to the Fourth Assessment Report of the Intergovernmental Panel on Climate Change. Cambridge: Cambridge University Press, 2007. 241-253 
[5]. Christine Maria Aranha Farias, Deforestation and the carbon sink role of forests: theoretical, empirical, and policy perspectives, Texas Tech Univerty, USA., 1997, p.1. 